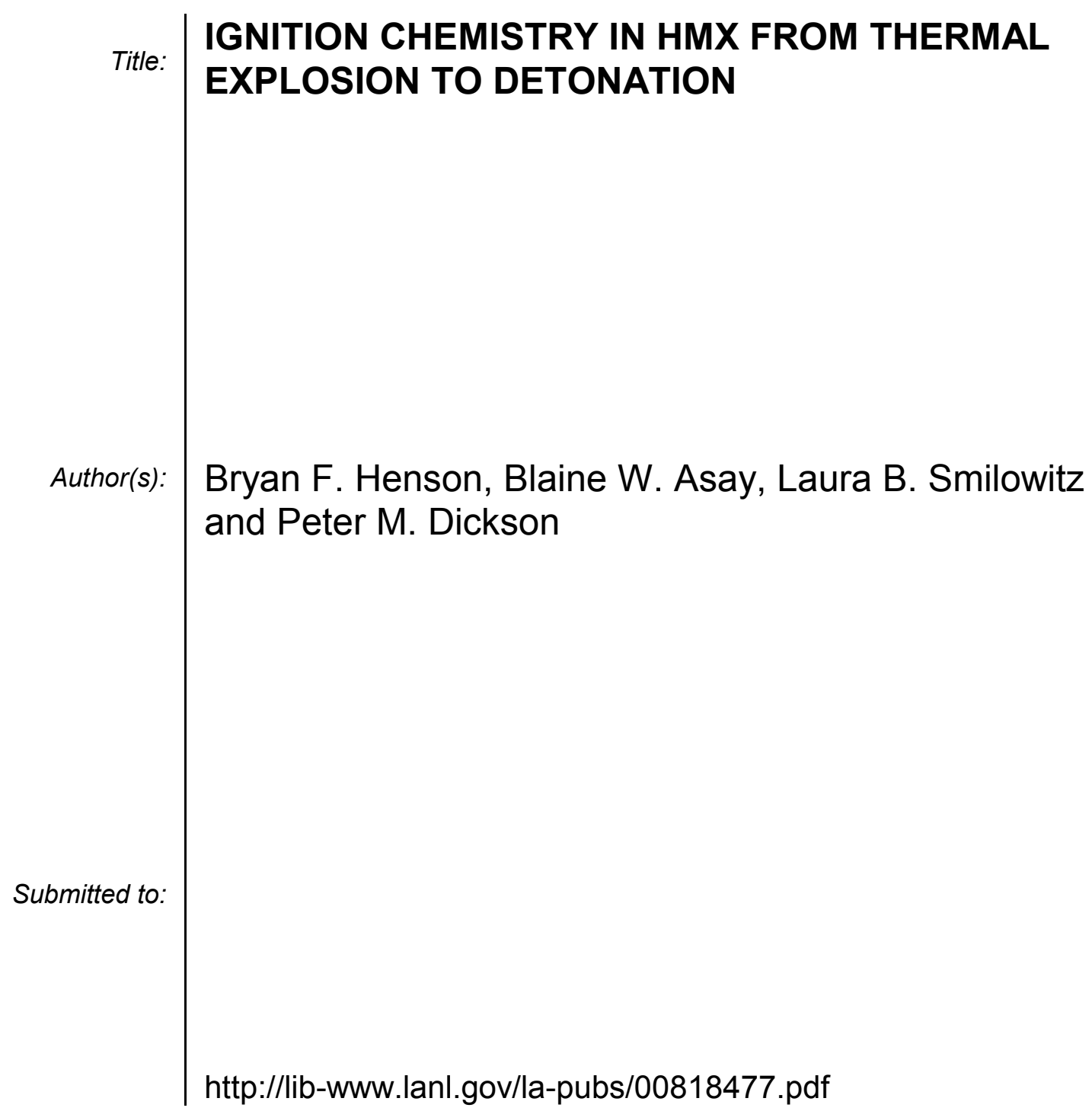

Los Alamos National Laboratory, an affirmative action/equal opportunity employer, is operated by the University of California for the U.S. Department of Energy under contract W-7405-ENG-36. By acceptance of this article, the publisher recognizes that the U.S. Government retains a nonexclusive, royaltyfree license to publish or reproduce the published form of this contribution, or to allow others to do so, for U.S. Government purposes. Los Alamos National Laboratory requests that the publisher identify this article as work performed under the auspices of the U.S. Department of Energy. Los Alamos National Laboratory strongly supports academic freedom and a researcher's right to publish; as an institution, however, the Laboratory does not endorse the viewpoint of a publication or guarantee its technical correctness. 


\title{
IGNITION CHEMISTRY IN HMX FROM THERMAL EXPLOSION TO DETONATION
}

\author{
Bryan F. Henson, Blaine W. Asay, Laura B. Smilowitz and Peter M. Dickson \\ Los Alamos National Laboratory, Los Alamos, NM 87545
}

\begin{abstract}
We present a global chemical decomposition model for HMX based materials. The model contains three component processes, the initial beta to delta phase transition, solid to gas decomposition and gas phase ignition, for which all kinetic and thermodynamic parameters are fixed by independent measurement. We present an isothermal ignition calculation over the range of temperatures from thermal explosion to detonation. The calculation is performed for a sphere of material and the critical diameter and time for ignition are determined. The sample diameter, and thus the balance of heat generation and dissipation, is the only degree of freedom in the calculation. The results of the calculation are in good agreement with data with respect to both the ignition times and length scales over the full temperature range of energetic response in HMX.
\end{abstract}

\section{INTRODUCTION}

It has long been known that HMX (octahydro1,3,5,7-tetranitro-1,3,5,7-tetrazocine) exhibits a wide variety of behaviors when subjected to various thermal fields. Temperatures just above $450 \mathrm{~K}$ induce explosion after an induction time from $10^{5}$ to $10^{1} \mathrm{~s}(1)$. IR laser irradiation generates surface temperatures from $500-700 \mathrm{~K}$ and ignition at $10^{-3} \mathrm{~s}$ to $10^{1} \mathrm{~s}(2)$. Shear or frictional heating of pressed solids to 700-900 K results in ignition in $10^{-4} \mathrm{~s}(3)$. Planar shocks from $10 \mathrm{GPa}$ to $30 \mathrm{GPa}$ result in detonation over times of $10^{-7} \mathrm{~s}$ to $10^{-6} \mathrm{~s}(4)$. Despite considerable progress in understanding the chemistry governing these processes, which span twelve decades in time, no comprehensive model of decomposition linking the separate regimes currently exists.

We first present a model independent compilation of ignition data from experiments on HMX based explosive formulations which indicates that a single decomposition model may be sufficient to reproduce the ignition chemistry of this material over the full range of energetic response, from thermal explosion to detonation. We then present a kinetic model of thermal decomposition based on the known chemistry of HMX and a simplified calculation of ignition that is in agreement with observation.

\section{COMPILATION OF IGNITION DATA}

We have collected data from experiments under conditions ranging from thermal explosion (1,5-7) and fast pyrolysis (8) to laser ignition (2) and impact induced shear and frictional heating (3). In addition, we include a classic set of detonation initiation experiments (9) where the heating profile from the confined surface of an HMX plastic bonded explosive was measured radiometrically subsequent to shock passage. In a separate publication we have extracted an experimentally constrained chemical rate constant for energy release from these experiments (10). Finally, using recent calculations of mean temperature in the detonation reaction zone of HMX we include the measured reaction zone time as an ignition time in stable detonation $(10,11,12)$.

The set of ignition data for HMX based samples is shown in Fig. 1. The data are compiled, with the exception of the detonation data, as the measured 
time to ignition as a function of the inverse of the applied temperature. The data set is to our knowledge inclusive, with the following exceptions. Some unconfined thermal explosion experiments have been neglected from the data set as the loss of reactant gases on long timescales can lead to spuriously long ignition times and even ignition in the gas phase away from the sample. In the fast pyrolysis data set of Brill and Brush (8) on thin films we have shown only the subset of data where reaction time was attributed to chemistry rather than thermal transport.

The simplest interpretation of such a linear fit in an inverse temperature plot is presence of a single rate limiting chemical step in the sequence of reactions leading to ignition. We fit the ignition data set of Fig. 1 using the classic Arrhenius form for the temperature dependence of the canonical rate constant $k=A \exp (-E / R T)$, where $k$ is a first order rate constant, $A$ a prefactor, $E$ the activation energy, $R$ the gas constant and $T$ the temperature. We assume the measured ignition times compiled in Fig. 1 to reflect a characteristic reaction time to ignition of $t=1 / k$, which is equivalent to assuming a first order rate law with ignition at a fractional decomposition of 1/e. The solid line of Fig. 1 is the result of a linear regression of the data set according to

$$
\ln (t)=\left(\frac{E}{R}\right) \frac{1}{T}-\ln (A)
$$

which yields values of $E=149 \pm 1.1 \mathrm{~kJ} / \mathrm{mole}$ and $A=\mathrm{e}^{29.35} \pm 0.26 \mathrm{~s}^{-1}$.

\section{CHEMICAL DECOMPOSITION MODEL}

The chemical decomposition model presented here is based solely on independently measured rate constants and thermochemical parameters. The model involves first a nucleation and growth mechanism describing the $\beta-\delta$ phase transition, followed by the formation of gas phase species approximately first order in the concentration of $\delta$ HMX and ending in a highly exothermic gas phase reaction mechanism initiated by bimolecular reaction of $\mathrm{NO}_{2}$ and $\mathrm{CH}_{2} \mathrm{O}$.

The set of coupled differential equations describing the evolution of the key chemical species $\beta$ and $\delta \mathrm{HMX}, \mathrm{NO}_{2}, \mathrm{CH}_{2} \mathrm{O}$ and $\mathrm{HCO}$ are given by

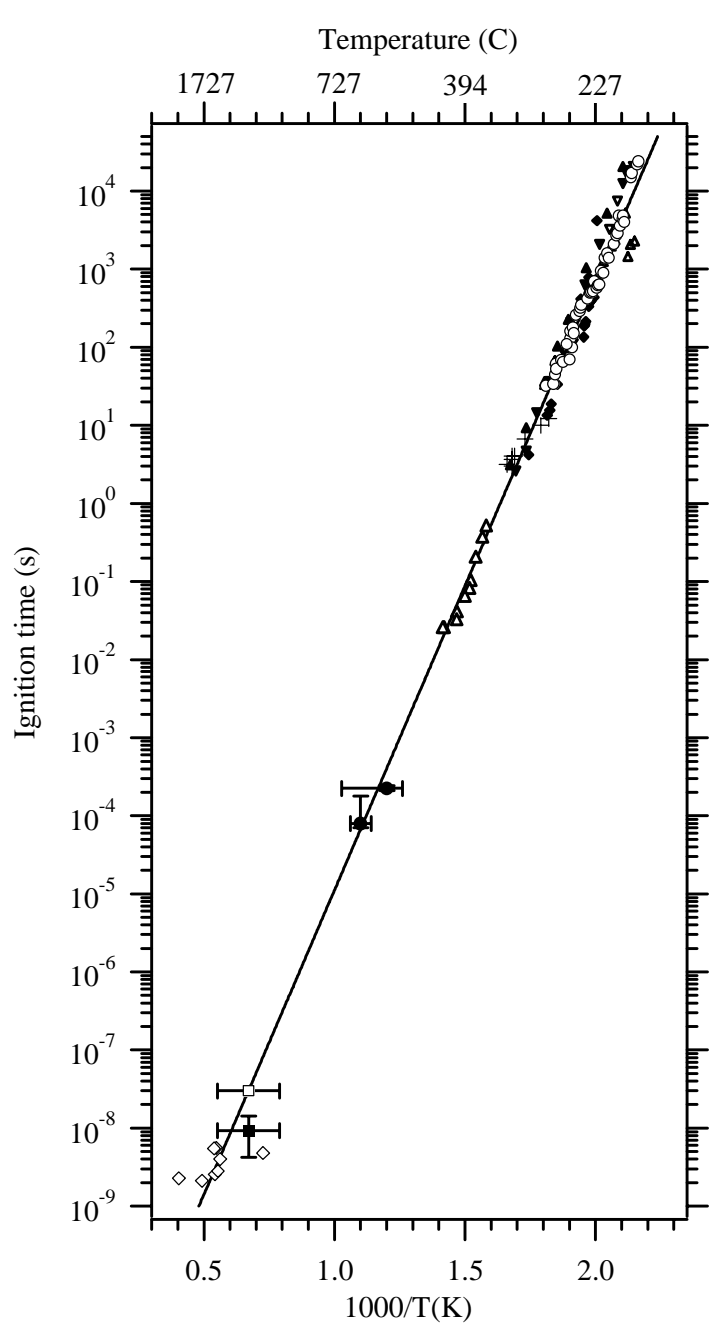

FIGURE 1. Ignition data from HMX compiled as follows: confined thermal explosion studies, filled diamonds (1), filled triangles and inverted triangles (5), open triangles and inverted triangles (6), and open circles (7), fast pyrolysis studies, crosses (8), laser ignition studies, open triangles (2), shear and frictional heating studies, filled circles (3), and detonation experiments, open diamonds (9), solid square (11) and open square (12). The solid line is the fit to the data using Eq. (1)

$$
\begin{array}{r}
\frac{\partial[\beta]}{\partial t}=-k_{1}[\beta]+k_{-1}[\delta]-\left(k_{2}-k_{-2}\right)[\beta][\delta] \\
\frac{\partial[\delta]}{\partial t}=k_{1}[\beta]-k_{-1}[\delta]+\left(k_{2}-k_{-2}\right)[\beta][\delta] \\
-k_{3}[\delta]
\end{array}
$$




$$
\begin{gathered}
\frac{\partial\left[\mathrm{NO}_{2}\right]}{\partial t}=2 \frac{k_{3 a}}{k_{3 a}+k_{3 b}} k_{3}[\delta]-k_{4}\left[\mathrm{NO}_{2}\right]\left[\mathrm{CH}_{2} \mathrm{O}\right] \\
-\left(k_{5 a}+k_{5 b}\right)\left[\mathrm{NO}_{2}\right][\mathrm{HCO}]
\end{gathered}
$$

$$
\begin{gathered}
\frac{\partial\left[\mathrm{CH}_{2} \mathrm{O}\right]}{\partial t}=4 \frac{k_{3 b}}{k_{3 a}+k_{3 b}} k_{3}[\delta] \\
-k_{4}\left[\mathrm{NO}_{2}\right]\left[\mathrm{CH}_{2} \mathrm{O}\right]
\end{gathered}
$$

$$
\begin{aligned}
& \frac{\partial[\mathrm{HCO}]}{\partial t}=k_{4}\left[\mathrm{NO}_{2}\right]\left[\mathrm{CH}_{2} \mathrm{O}\right] \\
& -\left(k_{5 a}+k_{5 b}\right)\left[\mathrm{NO}_{2}\right][\mathrm{HCO}]
\end{aligned}
$$

The rate constants are given by

$$
k_{i}(T)=e \frac{k_{B} T}{h} Q \exp \left(\frac{T D S^{*}-D H^{*}}{R T}\right)
$$

where $k_{i}(T)$ is a canonical rate constant in $\mathrm{s}^{-1}$ or $\mathrm{cm}^{3} /$ mole $\mathrm{s}$, depending on reaction order, $T$ the absolute temperature, $k_{B}$ and $h$ are Boltzman's and Plank's constants respectively, $H_{i}{ }^{*}$ and $S_{i}{ }^{*}$ are the activation enthalpy and entropy of the activated state, $R$ is the gas constant and $e$ is the base of the natural logarithm. $Q$ is an equilibrium constant relating the concentrations of the activated species to reagents. The parameter values used in the calculation are given in Table 1.

\section{IGNITION CALCULATION}

The calculation of ignition time, which will be detailed in a future publication, was performed as follows. The coupled set of differential equations describing the chemical model, Eqs. 2-6, was solved starting from an initial temperature $T_{\mathrm{o}}$ and density, $\rho_{\mathrm{i}}$ $=0.0063 \mathrm{moles} / \mathrm{cm}^{3}$. At each time step the amount of heat liberated or consumed was determined from the incremental concentration change and corresponding heat of reaction, taken from the literature. The multiphase character of the system and the relevant length scale for thermal diffusion were incorporated into the calculation by introducing a thermal loss term

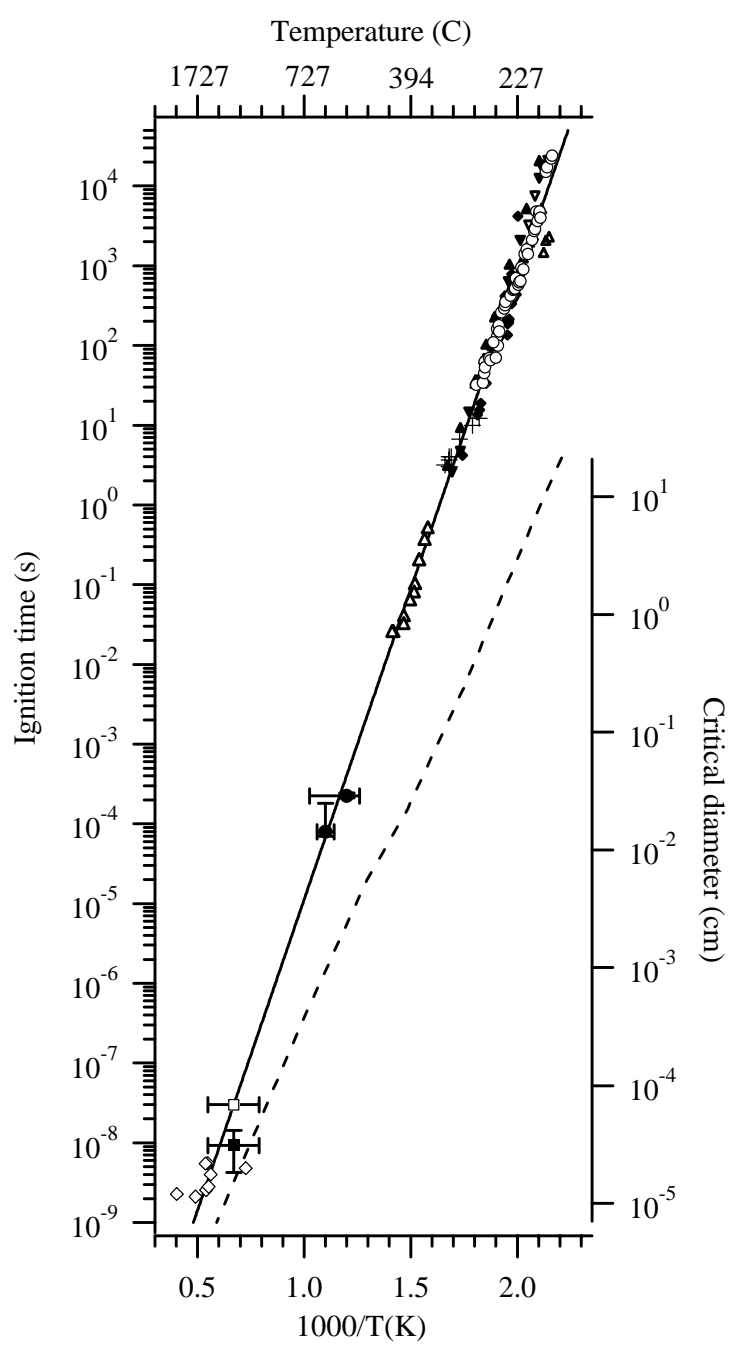

FIGURE 2. Ignition data from HMX as in Fig. 1. The solid line is the calculated time to ignition and the dashed line the critical diameter.

$$
\frac{1}{\pi d^{2}\left(1-\frac{[\beta]+[\delta]}{\rho_{i}}\right)} \frac{6 l}{C_{p} \rho}
$$

where $d$ is diameter, $\rho$ the density, $C_{\mathrm{p}}$ the system heat capacity and $l$ the thermal diffusivity. This term applies a diameter to the problem which defines the length scale for the calculation. The term $1-([\beta]+[\delta]) / \rho_{\mathrm{i}}$ is the fraction of the initial density that has converted to gaseous species. The heat capacity of the system is calculated as a 
weighted average of solid and gaseous components from this fraction.

The calculation is run at the initial $T_{\mathrm{o}}$ and $\rho_{\mathrm{i}}$ as a function of $d$ until a critical diameter, $d_{\mathrm{c}}$, is determined for ignition (i.e. for $d<d_{\mathrm{c}}$ no ignition is observed). The time to ignition is then determined for this diameter. The resulting ignition time as a function of temperature is shown as the solid line in Fig. 2. Also shown in Fig. 2 is the critical diameter determined for each temperature.

TABLE 1. Rate constant parameterization of Eq. 7

\begin{tabular}{|l|l|r|r|}
\hline & \multicolumn{1}{|c|}{$\mathrm{Q}$} & \multicolumn{1}{c|}{$\begin{array}{c}\Delta \mathrm{S}^{*} \\
\mathrm{~J} / \mathrm{mole} \mathrm{K}\end{array}$} & $\begin{array}{c}\Delta \mathrm{H}^{*} \\
\mathrm{~kJ} / \mathrm{mole}\end{array}$ \\
\hline $\mathrm{k}_{1}$ & 1 & 159.57 & 213.8 \\
\hline $\mathrm{k}_{-1}$ & 1 & 136.81 & 204.0 \\
\hline $\mathrm{k}_{2}$ & $10^{-9}$ & 149.34 & 79.7 \\
\hline $\mathrm{k}_{-2}$ & $10^{-9}$ & 126.58 & 69.9 \\
\hline $\mathrm{k}_{3}$ & 1 & -0.84 & 141.0 \\
\hline $\mathrm{k}_{3 \mathrm{a}}$ & 1 & 38.47 & 178.0 \\
\hline $\mathrm{k}_{3 \mathrm{~b}}$ & 1 & -79.18 & 106.0 \\
\hline $\mathrm{k}_{4}$ & 1 & -24.29 & 57.0 \\
\hline $\mathrm{k}_{5 \mathrm{a}}$ & 1 & -0.51 & 0.0 \\
\hline $\mathrm{k}_{5 \mathrm{~b}}$ & 1 & -1.18 & 0.0 \\
\hline
\end{tabular}

\section{CONCLUSIONS}

The primary result presented here is the model independent existence of a single linear relationship in the ignition literature for HMX when compiled in a $\ln \mathrm{t}$ vs. 1/T Arrhenius plot. Such a linear relationship is strong evidence for a single rate limiting chemical step in the ignition mechanism that appears to persist over the entire range of energetic response. Such a result indicates the possibility of constructing chemical decomposition models of HMX which may of sufficient simplicity to be of use in large scale calculations and at the same time reproduce the behavior of the material with some accuracy.

In addition, the broad temperature range encompassed by this relationship provides severe constraints on models of decomposition. For instance, although the phase transition kinetics (13) and ignition mechanism involving $\mathrm{NO}_{2}$ and $\mathrm{CH}_{2} \mathrm{O}$ and $\mathrm{HCO}$ (14) utilized in this model have been studied in detail, the kinetics of delta phase decomposition to gas phase species is still uncertain.
In particular, the observation that gas phase species appear in two channels, involving either $\mathrm{NO}_{2}$ or $\mathrm{CH}_{2} \mathrm{O}$ and characterized by two rate constants (here $\mathrm{k}_{3 \mathrm{a}}$ and $\mathrm{k}_{3 \mathrm{~b}}$ ) (15) leads naturally to a competitive mechanism of formation from $\delta$-HMX. Such a mechanism, however, exhibits two limiting slopes in an Arrhenius plot and is not consistent with observation. We have utilized a first order decomposition of delta here, given by $\mathrm{k}_{3}$, and modified the appearance ratio of the two channels with ratios of $k_{3 a}$ and $k_{3 b}$. It is an interesting algebraic feature of the work in the literature that $\mathrm{k}_{3}$, which corresponds to the first order rate constant controlling ignition, may be set equal to $\sqrt{k_{3 a} k_{3 b}}$ to within the precision of the measurements. The details of the intermediate steps in this mechanism will be the subject of future work.

\section{REFERENCES}

1. J. Zinn and R. N. Rogers, J. Phys. Chem. 66, 2646 (1962).

2. G. Lengelle, A. Bizot, J. Duterque and J.- C. Amiot, Rech. Aerosp. 2, 1 (1991).

3. B. F. Henson, B. W Asay, P. M. Dickson, C. Fugard, and D. J. Funk, Eleventh Symposium (International) on Detonation, (1998).

4. LASL Explosive Property Data, Edited by T. R. Gibbs and A. Popolato (University of California Press, 1980).

5. C. M. Tarver, R. R. McGuire, E. L. Lee, E. W. Wren and K. R. Brein, Seventeenth Symposium (International) on Combustion, (1978).

6. R. R. McGuire and C. M. Tarver, Seventh Symposium (International) on Detonation, (1981).

7. C. M. Tarver, S. K. Chidester and A. L. Nichols, J. Phys. Chem. 100, 5794 (1996).

8. T. B. Brill and P. J. Brush, Seventh Symposium (International) on Detonation, (1981).

9. W. G. Von Holle and C. M. Tarver, Seventh Symposium (International) on Detonation, (1981).

10. Occam's razor and detonation: Evidence for thermal equilibrium in the detonation of $H M X, \mathrm{~B}$. F. Henson, L. Smilowitz, B. W Asay, P. M. Dickson and P. M. Howe, submitted to Phys. Rev. Lett.

11. R. L. Gustavsen, S. A. Sheffield, and R. R. Alcon, Eleventh Symposium (International) on Detonation, (1998).

12. L. G. Green and E. James Jr., Fourth Symposium (International) on Detonation, (1965).

13. L. Smilowitz, B. F. Henson, B. W Asay and P. M. Dickson, to be submitted to J. Chem. Phys.

14. C.-Y. Lin. H.-T.Wang, M. C. Lin and C. F. Melius, Int. J. Chem. Kin.22, 455 (1990).

15. T. B. Brill, H. Arisawa, P. J. Brush, P. E. Gongwer and G. K. Williams, J. Phys. Chem. 99, 1384 (1995). 